afforded by the effects produced by the stimulants and other remedies administered. From the facts thus observed they judge of the propriety of increasing or diminishing the doses of their remedies, or altering the treatment. As practitioners, we shall surely exercise our calling with more security to our patients and satisfaction to ourselves by following this course, than by attempting to frame our own pructice, or teaching, on the basis of statistical figures, which, however honestly deduced and collated, often conceal errors which it is not possible to allow for or to eliminate.

I am, Sir, your obedient servant,

King's College, London, Nov. 1860 .

Lroner S. Beale

\section{POOR-LAW SURGEONS AND CAPITAT OPERATIONS.}

To the Editor of THE LANCET.

SIR,-I send you the copy of a letter I have received from the Poor-law Board, regarding the payment for assistance required for the performance of capital operations, from which you will see that it is the duty of the medical officer to pay for such assistance out of his own pocket, with a remote prospect (if he be extremely humble) of receiving "a gratuity" from the Poor-law guardians. I certainly am not surprised that the Commissioners should imagine that a gratuity in my case would be extremely acceptable, seeing I receive the magnificent sum of $£ 30$ per annum for the medical attendance upon a district containing some 12,000 people, principally colliers, and extending over an area of about thirty-six square miles. Perhaps, Mr. Editor, some of your readers, versed in figures, may be able to calculate the amount of my profits, after all expenses are paid. I certainly am at a loss to find even the fraction of a farthing. Some of them may be also able to inform me what the Commissioners mean by saying the medical officer would not be justified in refusing to operate, "unless the operation were one which it would be physically impossible for him to undertake." I think everyone will agree that' a man undertaking the duties of such a district as mine must be physically capable of working night and day, and therefore it may be fairly inferred that he is physically capable of performing any operation which any one man is capable of performing; but, on the other hand, everyone allows that there are operations which it is physically impossible for any one man to perform, and therefore, as I understand their opinion here given, I should be justified in such cases in refusing to operate; but in the very next sentence they state that, if I cannot perform them myself, I must procure the requisite assistance, and pay for it out of my own pocket. To me the meaning of their letter is certainly very obscure; but it is plain enough so far as this, that (as usual) there is to be no pay, unless as a gratuity from the guardians, and I am not one to ask it from the Cockermouth Board; I have known them too long and too well ever to think of doing anything so foolish.

In conclusion, it is only fair that I should state that the Maryport Local Board twice passed the account, and stated that, in their opinion, it was only reasonable that I should, or rather I ought to say that Mr. Curtis should, be paid for his services.

I remain, Sir, yours truly,

Marpport, November, $1860 . \quad$ JoseprI PeARson, M.D. Edin.

(COPY.)

Poor-law Board, Whitehall, S.W., Oct. 23rd, 1860

SIR, - I am directed by the Poor-law Board to acknowledge the receipt of your letter of the 5th ultimo, in reply to their communication dated the 4 th ultimo, respecting the claim which you have made upon the guardians of the Cockermouth Union in respect of the assistance which $\mathrm{Mr}$. Curtis rendered in the amputation of the thigh of a poor person named Stewart.

With reference to your first inquiry, I am directed to state that, in the opinion of the Board, it is the duty of a medical offcer to perform any operation which may be requisite in the case of a poor person whom he is attênding, under an order of the guardians or other competent authority, and that he would not be justified in refusing to do so, unless the operation were one which it would be physically impossible for him to undertake, or which he did not feel competent to perform. In the latter case it would be his duty at once to notify the circumstance to the guardians.

As regards your inquiries numbered 2 and $3, I$ am to inform 496 you that the Board consider that, as a general rule, a medical officer is only entitled to receive for his services in the cases specified in Article 177 of the General Consolidated Order the extra fees prescribed by that article, and that it is contem. plated that he should himself provide the assistance which he may deem to be necessary in any operation.

The Board direct me at the same time to state, that in any case in which a medical officer has obtained professional assistance, he can submit the facts to the guardians, with whom it will rest to determine whether the case was of such an exceptional character as to warrant them in proposing the payment of a gratuity to the medical officer under the provisions of Article 17 of the Regulations.

The Board do not feel that they can interfere further in respect to the case of Mrs. Stewart.

I am, Sir, your obedient servant, G. Grupin, Secretary.

J. Pearson, MI.D., Medical Officer, Mraryport.

\section{NEW METHOD OF REDUCING STRANGULATED} HERNIA.

To the Editor of THE LANCET.

SIR,- - I have received several interesting communications in acknowledgment of the paper you did me the honour to publish on the $20 \mathrm{th}$ ult., concerning a new method of reducing stran. gulated hernia. I consulted every work on hernia and surgery within my reach, and could find no reference made to any similar proceeding in such cases. There is, however, " nothing new under the sun," and I am perfectly satisfied to have been the means of resuscitating a mode of treatment not absolutely novel, but long neglected, and now, I trust, likely to become an acknowledged surgical proceeding.

My friend, Mr. Mayou, of Monmonth, informs me that, thirty years ago, when practising in Leicestershire, he adopted a plan like to that mentioned in my paper, at the instigation of the late Sir E. Phillimore, in a presumed case of intussusception; and that the patient recovered. I am further told-and I have no reason to doubt the correctvess of my information-that so far back as the time of Hey some such mode of proceeding was referred to in his Clinical Lectures of that period.

The letters which have appeared in your journal refer to cases occurring, or snggestions and experiments thought of previously to the appearance of my paper. The existence of them, or of any report of them, was entirely unknown to me.

I mentioned the subject to several of the most eminent surgeons in town, all of whom approved of the practice, but not one had heard of such a mode of treatment in strangulated hernia. Mr. Paget stated that it reminded him of something he had read years back in an old German work: that in such cases patients were sometimes placed upon a beer-barrel, and so rolled backwards and forwards for the purpose of liberating the rupture.

I regret that the publication of Mr. Hodge's case was un. known to me, and I feel much indebted to Dr. Millar for drawing my attention to its existence. Now that the subject has been well ventilated, we shall doubtless hear before long of many successful cases; and I trust that the text-hooks and manuals of surgery will recognise a plan which must assuredly prove a sterling addition to our means of treating such for midable accidents

I am, Sir, your obedient servant,

Royal-crescent, Cheltenham, Nov, 1860.

W ALTER J EsSOP, M.R.C.S.

P.S. - T have just succeeded in obtaining THE LANCET for Dec., 1849, containing Mr. Hodge's case. He states that, after many remedies had been tried, "the pain became so acute that the patient lay on the floor in the corner of the room, and raised his back against the wall, till at length he fairly stood on his head. After remaining in this position for a minute or two, the tumour receded without manipulation, and the hernia was reduced spontaneously. This occurred only a few minutes before my arrival." This case is very much to the point, but hardly, in all its bearings, analogous to the one I have reported.

\section{To the Editor of THe LANCET.}

SrR, - I have been much amused by the proof your valuable journal has recently afforded of the truth of the old saying, "There is nothing new under the sun." I allnde to the late publication of a new mode of treating strangulated hernia. I have for many years been in the habit of recording cases, as they occur, 